\title{
FREE SHRINKAGE OF WOOD DETERMINED AT THE CELLULAR LEVEL USING AN ENVIRONMENTAL SCANNING ELECTRON MICROSCOPE*
}

\author{
Giana Almeida ${ }^{1, \$}$, Françoise Huber ${ }^{2}$, Patrik Perré
}

In memoriam of Dr. Manfred SCHWANNINGER

\begin{abstract}
The shrinkage at the cellular level was determined in the transverse plane of wood using an environmental scanning electron microscope (ESEM). The whole procedure is based on pairs of images grabbed with the same imaging conditions (magnification, working distance, voltage) without removing the sample from the chamber: one image collected at saturated conditions $\left(1067 \mathrm{~Pa}, 1^{\circ} \mathrm{C}\right)$ and the other at air-dry state $\left(533 \mathrm{~Pa}, 16^{\circ} \mathrm{C}\right)$. A closed chain of the same reference points chosen from the anatomical markers was defined on both images at the external part of the zone of interest. A custom software program, called MeshPore, allowed the shrinkage coefficients to be extracted from the slight difference of shape between these two chains.

Measurements of transverse shrinkage were performed on earlywood and latewood zones from Norway spruce (Picea abies), only normal wood was studied. The interested zones were isolated from the rest of the annual ring with the aid of a microtome blade, insuring the observations to be done under free shrinkage. As additional features, the changes of the cellular morphology and the cell wall thickness were also evaluated thanks to the resolution provided by the ESEM.
\end{abstract}

Keywords: Cell wall thickness, cell shape, image correlation, MeshPore, softwood, Norway spruce.

\section{INTRODUCTION}

The shrinkage of wood is a macroscopic expression, at several spatial levels, of the solid/water behaviour and morphology of all components making up this material (multilayered cell wall, cell shape, ray cells, earlywood-latewood alternation...). Due to its influence in wood end-use, the dimensional variations, and particularly its transverse anisotropy (radial/tangential), has been the subject of considerable attention since several decades. In order to better understand the intricate coupling that exists between the spatial scales, and due to the biological origin of wood, measurements performed on sample with very small dimensions are required (Barkas 194, Boutelje 1962a,b, Kelsey 1963, Quirk 1982, Kawamura 1984, Watanabe et al. 1998a, Watanabe et al. 1998b, Badel and Perré 2001, Perré 2007). Wood is a material coming from a living organism, thus its physical-mechanical properties are highly influenced by the tree's history and age. For example, several works related different shrinkage behaviour of juvenile × "mature" woods and reaction $\times$ "normal" wood (Panshin and De Zeeuw1980, Timell 1986, Zobel and Sprague 1998). Almeida et al. (2008) used a very accurate equipment to measure tangential and longitudinal shrinkages on normal and reaction (compression) woods of spruce. They observed that in normal wood, total longitudinal shrinkage was near $0,45 \%$ whereas the tangential one

\footnotetext{
*This paper was originally presented at the 12th International IUFRO Wood Drying Conference July 30 to August 03, 2012 - Belém, Para, Brazil.

${ }^{1}$ UMR 1145, AgroParisTech, INRA, CNAM, 1 avenue des Olympiades, 91744 Massy, France

${ }^{2}$ UMR 1092, INRA, 14 rue Girardet, 54042 Nancy, France

${ }^{3}$ EcoleCentrale Paris, LGPM, Grande Voie des Vignes, 92290 Châtenay-Malabry, France

^Corresponding author: giana.almeida@agroparistech.fr

Received: 12.09. 2012 Accepted: 08.09. 2013
} 
was about $9 \%$. In the compression wood of spruce, the total longitudinal shrinkage was more than $2 \%$, whereas the tangential one was of 3,5\%. Such high difference between normal and reaction woods can causes significant problem during drying. Indeed, the chemical properties and anatomical structure of juvenile and reaction woods (specially the tracheids and fibers elements) are very different from those of "normal" woods.

Mariaux (1989) suggested that the anatomical pattern was of importance, as it is made up of different cell types which all play specific roles in shrinkage. For example, he observed that the transverse anisotropy of tissues depended on mean cell elongation, but that shrinkage was not isotropic for "isotropic" cells (same mean diameter in both the radial and tangential directions). In softwood, tangential shrinkage of earlywood is very often greater than radial shrinkage (Botosso 1997). By contrast, this author reports that the tangential shrinkage is less marked than radial shrinkage in reaction wood from the same species.

Perré and Huber (2007) proposed a new method to measure free shrinkage of very small areas. To achieve this, the tissue of interest is isolated from the rest of the material (in terms of kinematics) thanks to a diamond wire sawn. An image of this zone (R-T plane) is then grabbed at a certain water content (generally at saturation) and then at a different water content (in this case, in air-dry state). The difference between the two states makes it possible to determine the relative shrinkage of different tissues, or the anisotropy factor between two directions included in the image. To determine this shrinkage accurately on these isolated zones, specific routines have been added to the software MeshPore previously developed in our team (Perré 2005). Shrinkage is thus calculated from contour integrals over closed chains of reference points selected in the external part of the selected zone.

The environmental scanning electron microscope (ESEM) is an excellent way to visualize hygroscopic materials with high spatial resolution and minimum sample preparation. This instrument permits the content of water vapor in the sample chamber to be controlled. Thanks to the presence of gas in the sample chamber, the gas molecules are ionized by electrons traversing the chamber, generating positive ions which drift back towards the sample, thereby alleviating the build-up of charge which would otherwise occur in classical SEM. This charge compensation obviates the need for a conductive coating (Donald et al. 2003).

In this study, transverse shrinkage measurements were performed on earlywood and latewood zones of Norway spruce, only normal mature wood was used. Longitudinal shrinkage was not measured since it is considered as negligible in normal wood compared to that observed in radial and tangential directions (Almeida et al. 2008).Thus, the interested zones were carefully isolated from the rest of the annual ring with the aid of a microtome blade, permitting the cells to actually behave as separated zones. The software developed by Perré (2005) was used to determine the shrinkage at cellular level. This possibility to measure shrinkage on intact specimens, in spite of their very small size, the good control of the atmosphere condition inside the sample chamber and the mathematical approach used to measure the shrinkage values are certainly among the key features of our method. 


\section{MATERIAL AND METHODS}

\section{Material}

The studies were performed on wood from two mature spruce (Picea abies) trees. One tree (spruce 1) came from a forest near Nancy, France. The other (spruce 2) came from a natural stand in the Vosges, France. Samples came from breast height discs and were chosen with great care to avoid juvenile wood and reaction wood, so the select zones contained only normal mature wood (more than 20 rings from the pith). The average tree-ring width was 3,5 $\mathrm{mm}$ for spruce 1 and 2,5 $\mathrm{mm}$ for spruce 2 .

\section{a) Samples preparation}

Blocks with transversal section of $5 \mathrm{~mm}^{2}$ (radial $\mathrm{x}$ tangential directions) and about $8 \mathrm{~mm}$ long (longitudinal direction) were cut using a diamond wire microsaw (Well model 3241, Escil). The tangential sections were surfaced using a sliding microtome (Microm HM 440 E). Earlywood and latewood zones were tangentially separated by hand using a microtome blade under a binocular microscope. Four mm deep splits were made in the tangential-longitudinal plane, so that the tissue remained fixed to its own substrate while allowing free shrinkage at the level of the cells measured in their transversal surface. This precaution was particularly necessary to avoid tangential coupling in a zone where the density varied rapidly along the radial direction.

\section{b) Image acquisition}

Experiments were made using an ESEM FEI, Quanta 200, with a tungsten filament. The sample was fitted within a custom aluminum support positioned under a Peltier stage. This support was designed to insure a uniform temperature of the sample. This device was put inside the microscope chamber. The temperature of the sample (controlled by the Peltier stage) and the pressure of water vapor in the chamber where chosen to have samples equilibrated at two contrasted hygroscopic conditions: air dried $\left(16^{\circ} \mathrm{C}\right.$, $533 \mathrm{~Pa})$ and saturated $\left(1^{\circ} \mathrm{C}, 1067 \mathrm{~Pa}\right)$. Under these conditions, the relative humidity inside the sample chamber is close to $30 \%$ and $100 \%$, respectively. Indeed, in the saturated conditions, the water starts to condense onto the sample. Due to the minute size of samples, the equilibrium state was easily attained without remove the sample from the microscope chamber. In order to allow a quantitative comparison of the images taken in air dried and saturated states, all imaging parameters were kept constant (accelerating voltage of $8 \mathrm{kV}$, bean size 5 of and working distance of $7 \mathrm{~mm}$ ). Therefore, the imaging conditions were not optimal for each condition, but resulted from a compromise allowing for a reasonable quality in both conditions. One has to notice here that this protocol is mandatory to measure shrinkage with an electron scanning microscope, as the image magnification and the scale bar provided by the software guarantees only an accuracy of 3\% (manufacturer specifications).

\section{c) Shrinkage measurement}

The present work applies a methodology proposed in Perré and Huber (2007). Shrinkage in each sub-unit was determined by comparing the two images obtained of this zone. The mechanics of continuum media tells us that these two images are separated locally by a translation, a rotation and a pure deformation. The latter, induced by shrinkage, is in this case the datum of interest.

The method used to extract the shrinkage values from the two closed contours is based on Stokes' theorem:

$$
\oint_{\mathrm{c}} \mathbf{A} \cdot \mathrm{d} \mathbf{r}=\iint_{\mathrm{S}}(\nabla \times \mathbf{A}) \cdot \mathrm{d} \mathbf{S}
$$

where $\mathrm{S}$ is an open surface limited by a closed curve $\mathrm{C}$. 
Simple formulae derive from this theorem when the surface is in a plane. In particular, the mean values for $\varepsilon_{11}$ and $\varepsilon_{22}$ on surface $S,\left\langle\varepsilon_{11}\right\rangle$ and $\left\langle\varepsilon_{22}\right\rangle$, which are the two shrinkage values, are defined as follows

$$
\begin{array}{r}
\left\langle\varepsilon_{u}\right\rangle=\left\langle\frac{\partial u}{\partial x}\right\rangle=\frac{1}{S} \iint_{S} \frac{\partial u}{\partial x} d x d y=\frac{1}{S} \oint_{C} u \cdot d y \\
\left\langle\varepsilon_{22}\right\rangle=\left\langle\frac{\partial v}{\partial y}\right\rangle=\frac{1}{S} \iint_{S} \frac{\partial v}{\partial y} d x d y=-\frac{1}{S} \oint_{C} v, d x
\end{array}
$$

The surface area $\mathrm{S}$ is obtained using a similar expression

$$
S=\oint_{C} x \cdot d y=-\oint_{C} y \cdot d x
$$

In equations (2) and (3), $\mathrm{u}$ and $\mathrm{v}$ are the point displacements along $\mathrm{x}$ and $\mathrm{y}$ axis, respectively.

The software program MeshPore, developed by Perré (2005), was used to achieve this manual referencing on the images and subsequently performing the contour integral to extract shrinkage coefficients. The work on a pair of images started by plotting a chain of material points, chosen as anatomical marks of the tissue, on the initial image (Figure 1a). To allow the mathematical treatment presented below, this chain must be closed. It is duplicated before moving on to the deformed image. By translating this duplicated chain, one of the reference points was placed at the correct position on the deformed image. It was then necessary to shift each point in the chain slightly to the new position of the anatomical mark (Figure 1b). Finally, the tangential and radial shrinkages were automatically calculated by the command "strain" (Figure 1c). 

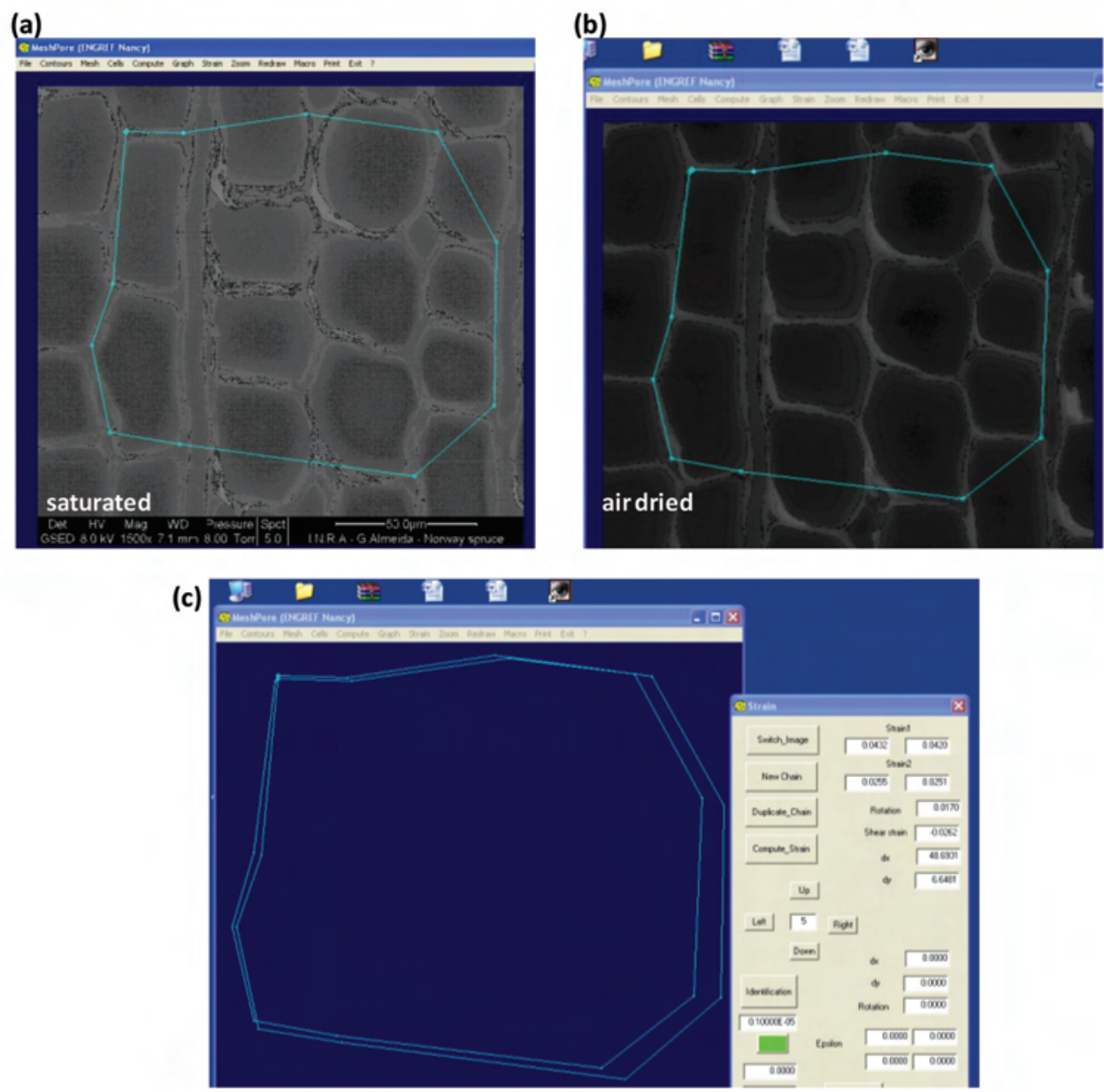

Figure 1. Example of two images (initial (a) and deformed (b)) and the corresponding chains of points plotted using the software MeshPore (Perré 2005) and the two chains treated to determine the strain values (c). This example corresponds to image of Picea abies 2 (earlywood).

\section{RESULTS AND DISCUSSION}

Table 1 summarizes the results obtained from the analysis of several images taken inside one annual ring of each spruce tree. Tree 2 has higher shrinkage averages for both earlywood and latewood zones.

Results presented in table 1 confirm the large anisotropy of earlywood, and this for both trees studied ( $\mathrm{T} / \mathrm{R}$ ratio of 2,0 and 2,8 for trees 1 and 2, respectively). One the contrary, in latewood zone, tree 1 becomes almost isotropic (T/R ratio of 0.9 ) and the anisotropy of tree 2 is inverted (radial shrinkage higher than tangential). Perré and Huber (2007) obtained similar results when studying shrinkage of spruce. These authors presented the following results: earlywood had a marked anisotropy $(T=5,42 \%$ and $\mathrm{R}=2,14 \%$ ); latewood was separated into two zones (LW1 and LW2), where LW1 was almost isotropic ( $\mathrm{T}=8,33 \%$ and $\mathrm{R}=5,87 \%)$ and $\mathrm{LW} 2$ had an inverted anisotropy $(\mathrm{T}=4,35 \%$ and $\mathrm{R}=7,80 \%)$. They explained this different shrinkage behaviour of the latewood zones by the morphology of the cells, thus, LW1 containing cells with thick walls conserving sustained radial extension, and LW2, the terminal zone of latewood, which corresponded to a sudden lignification, without expansion, of all dividing cells of the cambial zone. 
Table 1.Complete data set collected on the two Picea abies trees (each line corresponds to one image).

\begin{tabular}{|c|c|c|c|c|}
\hline \multicolumn{2}{|c|}{ Sample } & $\begin{array}{c}\text { Tangential shrinkage } \\
(\%)\end{array}$ & $\begin{array}{c}\text { Radial shrinkage } \\
(\%)\end{array}$ & $\mathbf{T} / \mathbf{R}$ \\
\hline \multirow{14}{*}{ Earlywood } & \multirow{10}{*}{$\begin{array}{c}\text { Picea abies } \\
\text { I }\end{array}$} & 4,08 & 2,88 & 1,4 \\
\hline & & 2,34 & 1,14 & 2,1 \\
\hline & & 3,21 & 1,78 & 1,8 \\
\hline & & 2,60 & 2,18 & 1,2 \\
\hline & & 2,36 & 1,76 & 1,3 \\
\hline & & 2,51 & 1,78 & 1,4 \\
\hline & & 2,47 & 0,63 & 3,9 \\
\hline & & 3,83 & 1,46 & 2,6 \\
\hline & & 2,77 & 1,13 & 2,5 \\
\hline & & $2,91^{*}(10,65)^{* *}$ & $1,64(0,66)$ & $2,0(0,9)$ \\
\hline & \multirow{4}{*}{$\begin{array}{c}\text { Picea abies } \\
2\end{array}$} & 5,83 & 1,6 & 3,6 \\
\hline & & 4,32 & 2,55 & 1,7 \\
\hline & & 4,85 & 1,58 & 3,1 \\
\hline & & $5,00(0,77)$ & $1,91(0,55)$ & $2,8(1,0)$ \\
\hline \multirow{17}{*}{ Latewood } & \multirow{13}{*}{$\begin{array}{c}\text { Picea abies } \\
1\end{array}$} & 4,58 & 5,36 & 0,9 \\
\hline & & 4,3 & 6,52 & 0,7 \\
\hline & & 4,86 & 7,37 & 0,7 \\
\hline & & 3,62 & 4,98 & 0,7 \\
\hline & & 3,35 & 5,09 & 0,7 \\
\hline & & 4,52 & 6,78 & 0,7 \\
\hline & & 3,75 & 2,99 & 1,3 \\
\hline & & 4,07 & 2,94 & 1,4 \\
\hline & & 4,04 & 3,17 & 1,3 \\
\hline & & 3,32 & 2,92 & $\mathrm{I}_{2} \mathrm{I}$ \\
\hline & & 3,23 & 3,27 & 1,0 \\
\hline & & 3,07 & 3,88 & 0,8 \\
\hline & & $3,89(0,59)$ & $4,61(1,64)$ & $0,9(0,3)$ \\
\hline & \multirow{4}{*}{$\begin{array}{c}\text { Picea abies } \\
2\end{array}$} & 4,53 & 7,91 & 0,6 \\
\hline & & 5,25 & 5,83 & 0,9 \\
\hline & & 5,30 & 7,63 & 0,7 \\
\hline & & $5,03(0,43)$ & $7,12(1,13)$ & $0,7(0,2)$ \\
\hline
\end{tabular}

* Average. ** Standard deviation of the average.

The trend for the softwood tissues to become isotropic in latewood confirms the results obtained in the rare works devoted to shrinkage measurement of softwood tissues (Boutelje 1962a, Quirk 1982, Bosshard 1984, Watanabe et al. 1998a, Watanabe et al. 1998b, Mikajiri et al. 2001). Nevertheless, Perré et al. (2007) noticed that the important inverse anisotropy factor found in latewood is certainly due to the ability of their method to accurately determine shrinkage on samples comprising only a few cells in each direction. The present work corroborates this conclusion applying a methodology capable of studying an even smaller zone.

The data set of table 1 was plotted in figure 2 . In this figure, radial shrinkage $\left(\beta_{R}, y\right.$-axis) was reported as a function of tangential shrinkage $\left(\beta_{\mathrm{T}}, \mathrm{x}\right.$-axis). A logarithmic scale was chosen so the lines corresponding to isovalues of the anisotropy ratio could also be plotted as straight lines in the same graph. In this figure, the change of the anisotropic ratio from earlywood to latewood becomes obvious: the classical value of two (T/R ratio) generally measured of solid wood is observed at the tissue level for earlywood, while a ratio of about one, or even less than 1is observed for latewood. Coming back to separate shrinkage 
values, the two sets of data in figure 2 seems to prove than, roughly speaking, only the value of radial shrinkage changes (increases) from earlywood to latewood, the tangential shrinkage remaining almost unchanged. Keeping in mind that the formation of wood by the cambium keeps the tangential tracheid diameter constant throughout the annual ring, while the radial diameter reduces dramatically from earlywood to late wood, it is tempting to relay the shrinkage anisotropy to the geometrical geometry of tracheid, as Mariaux suggested years ago (Mariaux 1989).

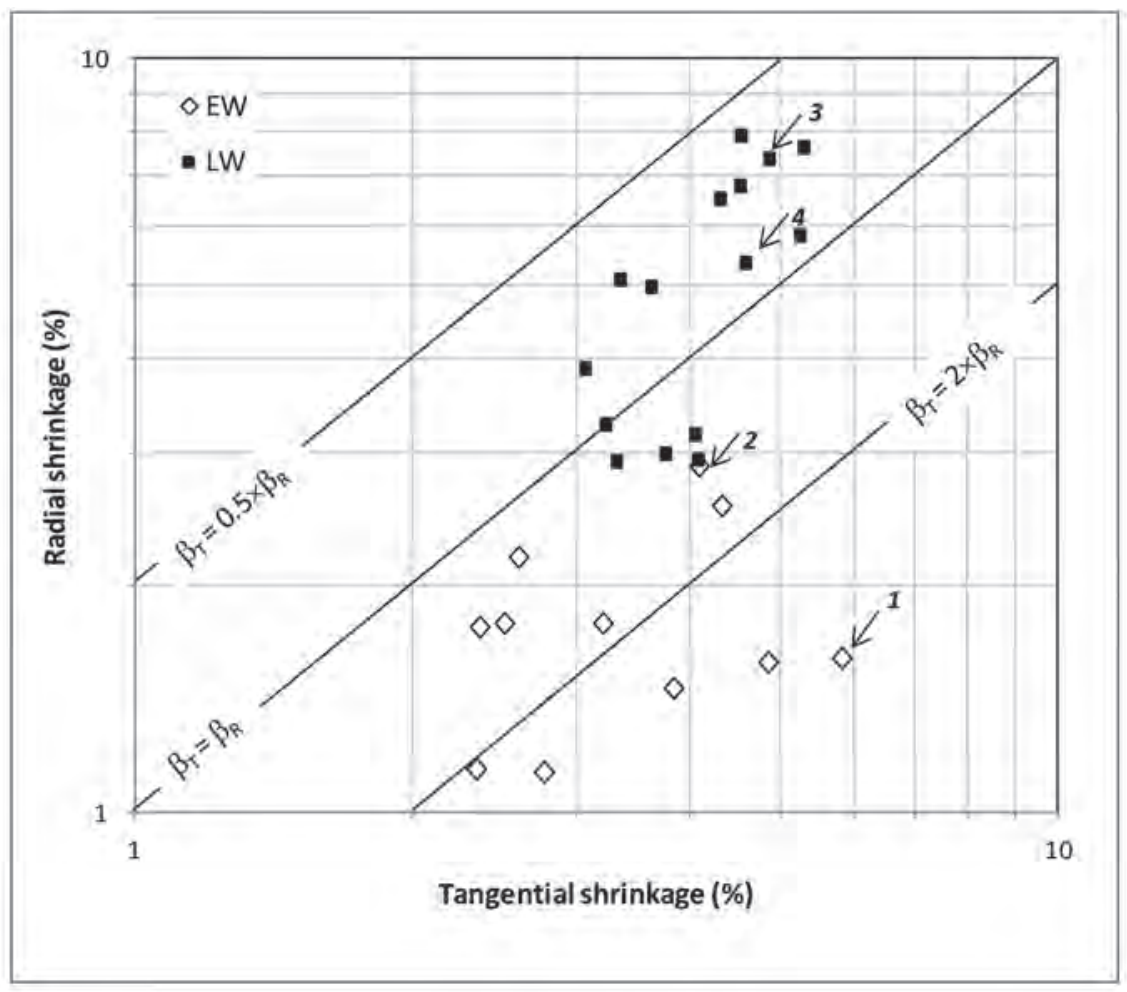

Figure 2. Radial shrinkage plotted versus tangential shrinkage for Picea abies (trees 1 and 2).

$\mathrm{EW}=$ earlywood, $\mathrm{LW}=$ latewood.

Numbers 1 to 4 indicate the images depicted in figures 3 and 4 . 
(a)

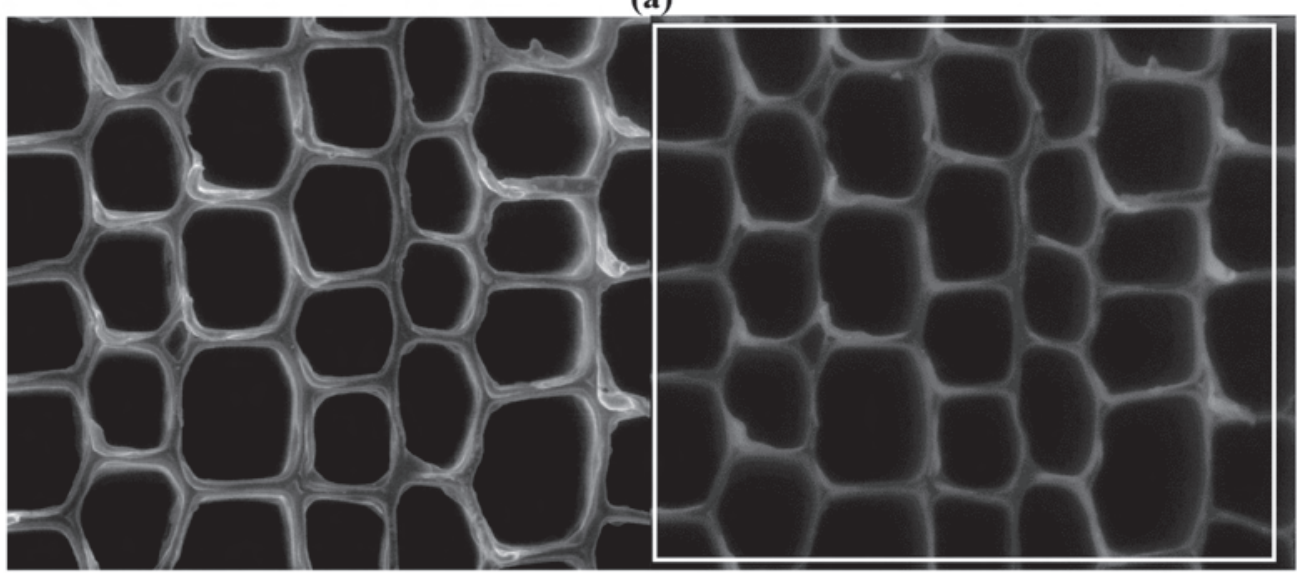

Saturated

Air dried $(\mathrm{T}=5.83 \% ; \mathrm{R}=1.60 \%)$

(b)

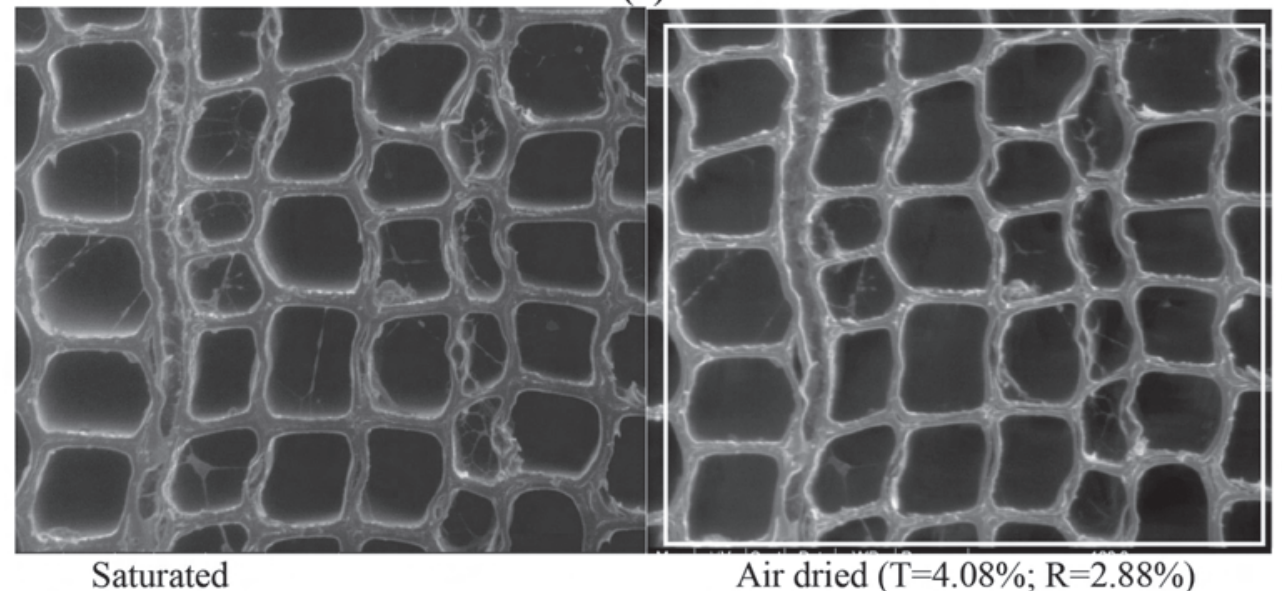

Figure 3. Example of saturated and air-dried images of earlywood zone.

(a) Image from tree 2 - number 1 on figure 2.

(b) Image from tree 1 - number 2 on figure 2.

White squares depict the dimension of the saturated image after drying. 
(a)

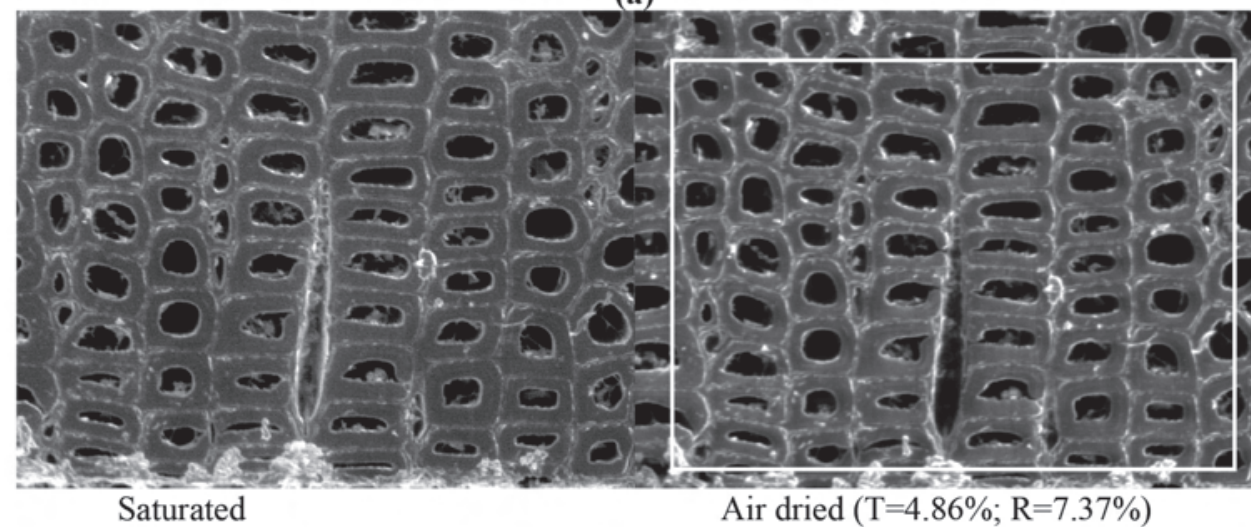

(b)

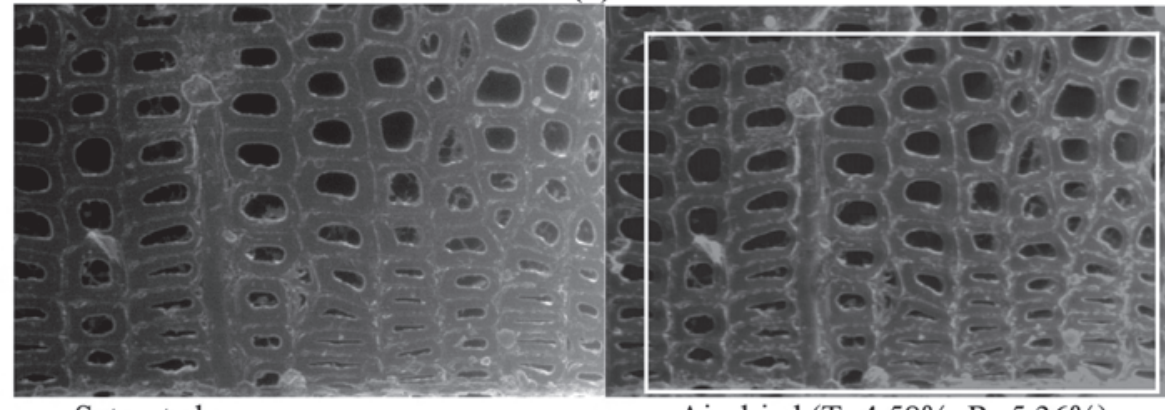

Saturated

Air dried $(\mathrm{T}=4.58 \% ; \mathrm{R}=5.36 \%)$

Figure 4. Example of saturated and air-dried images of latewood zone.

(a) Image from tree 1 - number 3 on figure 2.

(b) Image from tree 1 - number 4 on figure 2.

White squares depict the dimension of the saturated image after drying.

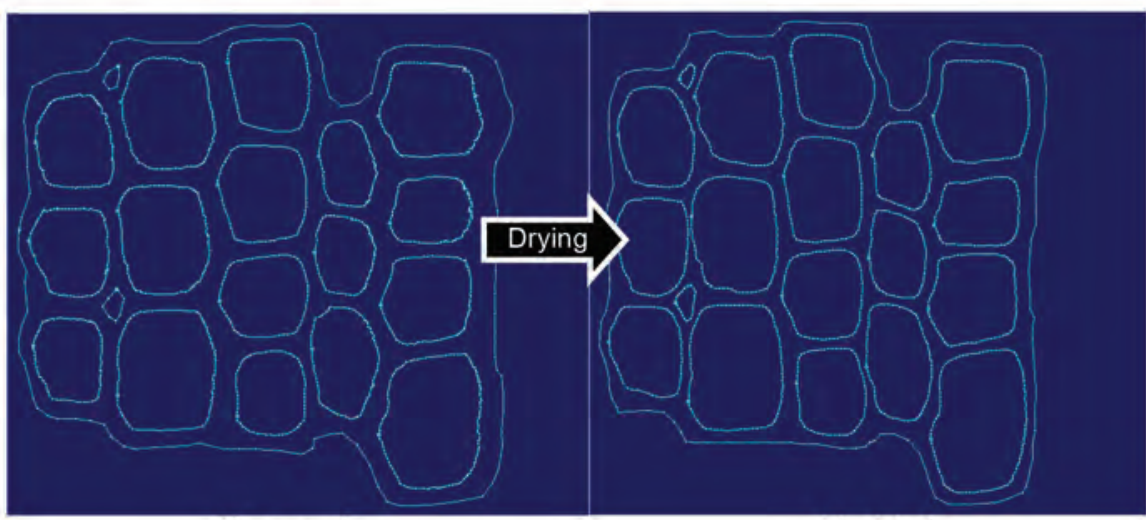

Saturated

Air dried

Figure 5. Cell wall contour of earlywood zone. Image used for cell wall thickness determination using MeshPore software (original images showed on Figure 3a). 


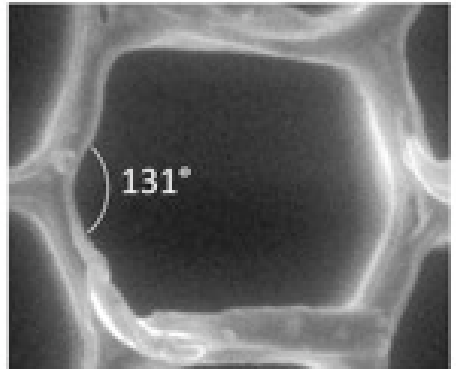

Saturated

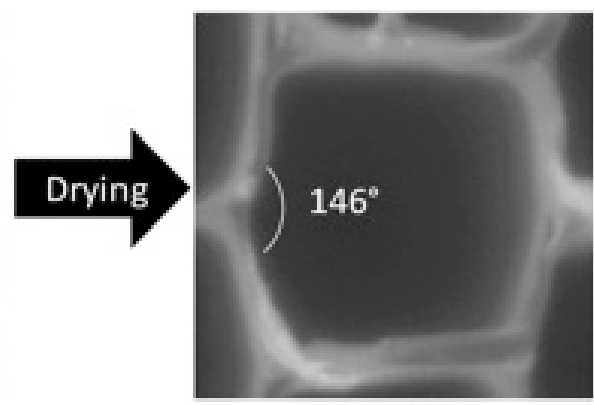

Air dried

Figure 6. Zoom of an earlywood tracheid showing the change of cell wall shape caused by drying.

In addition to averages value at the tissue level, the spatial accuracy of the ESEM allows local information, such as cell wall thickness and morphological changes due to drying, to be collected as well. In order to better illustrate the changes in cell morphology during drying, two sets of images were chosen for each zone (earlywood zone: images 1 and 2; latewood zones: images 3 and 4). Indeed, MeshPore is also capable of generating the cell wall contour (Figure 5) and calculating the cell wall thickness at saturated and air dried states. For example, the images showed in figure 5 (earlywood zone) presented an average cell wall of 3,6 $\mu \mathrm{m}$ at saturated state and of 3,0 $\mu \mathrm{m}$ at air dried state. Concerning the changes in cell shape caused by drying, figure 6 proves that earlywood cells present a hexagonal shape at saturated state and a rectangular shape at dried state. This morphology change, well explained by energy minimization, causes high tangential shrinkage values and explains the transversal anisotropy of earlywood. From a mechanical point of view, the shrinkage anisotropy in the transverse plane results from two cumulative effects:

- The local anisotropy of the cell wall properties,

- The cellular morphology, as resulting from the cambial activity which generated cell lines from each mother cell, with cell walls almost aligned along the radial direction and scattered along the tangential direction.

\section{CONCLUSIONS}

A novel method is proposed to measure the free shrinkage at the cellular level in the transversal plane (radial and tangential). Images are taken using an environmental scanning electron microscope. In order to measure free shrinkage on very small zones, sub-units were separated from each other on a common base, using a microtome blade under a binocular microscope.

The images collected were processed using a vectorial image analysis tool developed by our team. Specific functions were implemented in this software for the purpose of the present study, and notably the extraction of shrinkage values from closed chains of points connecting the same specific anatomical references on both images. 
Measurements were performed in one softwood species (Norway spruce). Among the main results, reference should be made to the high anisotropy of earlywood and the quasi-isotropic shrinkage of latewood (indeed, even inverted ratio for one specimen).Images taken from ESEM were also used to determine the cell wall thickness and morphological changes during drying. Thus, it can be concluded that shrinkage at the cellular level results from two coupled effects: cell wall properties (specially its local anisotropy) and cellular shape resulting from its formation in the cambium.

These data are valuable, firstly in order to validate modelling approaches regarding the shrinkage of different types of cell patterns, and secondly to predict the shrinkage of a whole ring by change of scale. Modelling works are currently in progress to quantify the respective effects of cell wall anisotropy and cellular morphology. This work could provide a theoretical framework to the observed relationship between shrinkage anisotropy and cell shape ratio (Mariaux 1989 and the present work).

\section{ACKNOWLEDGMENT}

This work was supported by the ANR (National Research Agency) ANALOG (ANRBLAN08-3_310735), France.

\section{REFERENCES}

Almeida, G.;Assor, C.; Perré, P. 2008. The dynamic of shrinkage/moisture content behavior determined during drying of micro-samples for different kinds of wood. Drying Technology 26:1118-1124

Badel, E.; Perré, P. 2001. Using a digital X-ray imaging device to measure the swelling coefficients of a group of wood cells. NDT\&E International 34:345-353.

Barkas, W. 1941. Wood water relationships, VI The influence of ray cells on the shrinkage of wood. Trans Faraday Soc 37:535-547.

Bosshard, H.H. 1984. Holzkunde.Vol 2, Zur Biologie, Physik und Chemie des Holzes, Birkhäuser, Basel 312p.

Botosso, P. 1997. Une méthode de mesure du retrait microscopique du bois : Application à la prédiction du retrait tangentiel d'éprouvettes de bois massif de sapin pectiné (Abies alba Mill.), Ph.D.thesis, Université Nancy I, France.

Boutelje, J. 1962. The relationship of structure to transverse anisotropy in wood with reference to shrinkage and elasticity. Holzforschung 16:33-46.

Donald, A.M.; Baker, F.S.; Smith, A.C.; Waldron, K.W. 2003. Fracture of Plant Tissues and Walls as Visualized by Environmental Scanning Electron Microscopy. Annals of Botany 92:73-77.

Kawamura, Y. 1984. Studies on the properties of rays III. Influence of rays on anisotropic shrinkage of wood. Mokuzai Gakkaishi 30:785-790.

Kelsey, K. 1963. A critical review of the relationship between the shrinkage and structure of wood. Division of Forest Products Technological 28, CSIRO, Melbourne. Australia. 35p.

Mariaux, A. 1989. La section transversale de fibre observée avant et après séchage sur bois massif. Bois et Forêts des Tropiques 221:65-76. 
Mikajiri, N.; Matsumura, J.; Okuma, M. 2001.Observations by LV-SEM of shrinkage and anisotropy of tracheid cells with desorption. Mokuzai Gakkaishi 47:289-294.

Panshin, A.J.; De Zeeuw, C. 1980. Textbook of wood technology. $4^{\text {th }}$ edition. New York: McGrawHill Book Company.722p.

Perré, P. 2005. MeshPore: A software able to apply image-based meshing techniques to anisotropic and heterogeneous porous media. Drying Technology 23:1993-2006.

Perré P. 2007. An experimental device for the accurate determination of wood-water relations on micro-samples. Holzforschung 61: 419-429.

Perré, P.; Huber, F. 2007. Measurement of free shrinkage at the tissue level using an optical microscope with an immersion objective: results obtained for Douglas fir (Pseudotsuga menziesii) and spruce (Picea abies). Ann For Sci 64:255-265.

Quirk, J.T. 1982. Shrinkage and related propertied of Douglas-fir cell walls. Wood Fiber Sci 16:115133.

Timell, T. 1986. Compression wood in Gymnosperms. Vol. 1-3, Springer-Verlag, Berlin 2150 p.

Watanabe, U.; Fujita, M.; Norimoto, M. 1998a.Transverse shrinkage of coniferous wood cells examined using replica method and power spectrum analysis. Holzforshung 52:200-206.

Watanabe, U.; Norimoto, M.; Fujita, M.; Gril, J. 1998b.Transverse shrinkage anisotropy of coniferous wood investigated by the power spectrum analysis. Journal of Wood Science 44:9-14.

Zobel, B.; Sprague, J.R. 1998. Juvenile wood in forest trees. Springer-Verlag, Berlin 300p. 